DISCUSSION.

Professor Remington-The subject of botany itself, except the coarser structure of plants and bacteriology, has passed from the curriculum of the medical colleges and is now taught as a primary branch in the pharmacy colleges. I think that there is very little probability of the restoration of medical botany to its former place in the medical school; but it is well to know that it is taken up in other schools.

Dr. PAQurN of St. Louis-The great difficulty in regard to the study of botany by medical men is want of time, but this must be provided for, as bacteriology is going to develop enor mously in the near future.

\section{PHARMACEUTIC CHEMISTRY, PHARMA. COLOGY AND PHARMACO-PHYSICS THE NATURAL STEPPING-STONES TO SCIENTIFIC MEDICINE.}

Presented in the Section on Materia Medfca, Pharmacy and Therapeutics at the Forty-eighth Annual Meeting of the American Medical Association held at Philadelpbia, Pa., June 1-4, 1897.

BY ALFRED R. L. DOHME, Ph.D.

BALTIMORE, YD.

Before entering upon a discussion of the subjects embraced by all the above caption, it might not be out of place to make clear what the exact meaning of the terminology that will come up for consideration is. Some little confusion has arisen recently, th because of the donble use of the word pharmacology, and the dictionaries do not help us out in the matter. They define pharmacology as the study of drugs both as to their recognition, properties and therapy. In other words, it is a general term for the study of drugs and their therapy, or a combination of pharmacy, the science of compounding drugs, with materia medica, the description of drugs and their medicinal effect. This is in accordance with the derivation of the word, which is made up of the Greek words, pharmakon and logos, meaning a discourse on or a study of drugs. However, the word has also been used, especially in Germany, to mean the study of the physiologic effect of drugs on the human system. Thus, when acetanilid is taken into the stomach and produces certain results or effects, it is the province of pharmacology to study and explain what organs, tissues, fluids, etc., of the body are affected by the same and in what way. Pharmaceutic chemistry has to do only with the chemistry of drugs, i.e., given a drug, say belladonna root, it is the province of pharmaceutic chemistry to discover entirely what the same contains and in what relative quantities, thus: atropin, hyoscyamin, hyoscin, starch, resins and which, fats and which, malic acid, etc. Pharmacognosy is the study of the various physical properties of drugs which will enable one to recognize them, including their history. It hence embraces their botany, microscopy, histology, the chemistry of their constituents and the history of their use as a drug. Pharmacodynamics is a term that has been employed to express the effect and uses of medicines, being derived from the Greek words pharmakon, a drug, and dynamikos, the power or effect, and is hence practically the same as therapeutics. In considering the study of the effects of drugs upon the human economy, it appears to me that we have to become acquainted with the following facts in order to get at a scientific knowledge of how drugs act. We should know all the constituents of the drug we desire to use; we should know the physiologic effect of every constituent of the drug we are administering and, then, use only those constituents, or preparations containing only those con- stituents that produce the effect we desire to produce; and we should know the cause of the effect of each of these constituents. The first embraces the pharmaceutic chemistry of the drug, the second its pharmacology and the third its pharmaco-physics, which last word I have coined, as I believe there exists no word to express the study of the causes of the effects of drugs. It would be well to make clearer, perhaps, the distinction intended to be conveyed by the terms pharmacology and pharmaco-physics, and a concrete example will best serve to do this. Let us take acetanilid, as this will serve our purpose quite well and is besides one of the most generally used drugs. The pharmaceutic chemistry of acetanilid is the study of its formation, properties and decompositions. Its pharmacology is the knowledge resulting from the study of its physiologic effect on all the organs, tissues, fluids, etc., of the body, thus making plain what effect it produces, when we administer it, on the heart, blood pressure, nerve centers, liver, kidneys, mucous membranes, blood, lymphatics, etc. Its pharmaco-physics is the knowledge resulting from the study of the cause of the effects observed in studying its pharmacology, and would represent the study of the physiologic effects of all the groups contained in the acetanilid molecule. Acetanilid is made up of the group of acetic acid or acetyl $\left(\mathrm{CH}_{3} \mathrm{CO}\right)$ and anilin $\left(\mathrm{C}_{6} \mathrm{H}_{5} \mathrm{NH}_{2}\right)$, which in turn is made up of the ammonia radical, amid $\left(\mathrm{NH}_{2}\right)$, and of benzene $\left(\mathrm{C}_{6} \mathrm{H}_{6}\right)$, a hydrocarbon produced by the destructive distillation of coal. The province of pharmaco-physics would be to discover whether the effects of acetanilid, which we observed in studying its pharmacology, were due to the acetyl group, the ammonia group or the benzene group; or, what is more probable, which of the various effects of acetanilid was due to each and all of these constituent radicals of the acetanilid molecule. This can be done very readily by varying the various radicals and observing the failing or modification of this or that effect. Thus, if the red corpuscles are precipitated, producing cyanosis and eventual collapse, is this due to the ammonia radical $\left(\mathrm{NH}_{2}\right)$, or the acetyl radical or to the benzene radical, present in the molecule? Further, if the blood pressure is diminished, to which of these radicals is this due, etc.? If this is tabulated and known, for the various drugs of our pharmacopeia, we will reach such a desired and advanced stage in our knowledge of medicines, that we can control the unpleasant and undesirable effects of our remedies entirely and produce and use only such remedies as will produce just the effects we desire and no other effects. This is not only true of synthetic remedies but of all remedies, inorganic as well as organic. No doubt this appears chimeric to many and beyond the limits of probability and also usefulness, because of its apparent complexity, but there can be no doubt at all that it is not only among the probabilities, but that it is the natural evolution of the science of medicine that will take place in the next fifty years. German schools of medicine are entering upon this enormous and as yet untrodden and fertile field of investigation, and we should give it the attention that its importance merits. It is not a matter that can be taught, because it is as yet an unknown or practically unknown science, but it can and should be made the subject of investigation and study, so that we may become acquainted with the facts that it will give us, and enable us to make use of them in administering medicines. How few physi- 
cians today know the exact effect of the medicines they prescribe on the various organs, and what is the cause of that effect? They know that jaborandi produces activity of certain glands, resulting in increased secretions thereby, and they know that the pilocarpine in these leaves produce this effect, but do they know what other effects pilocarpine produces on the other organs, say on the blood, liver, kidneys, etc., and do they know what causes pilocarpine to produce this effect? They may say that it is not necessary for them to know this, as the effect is produced just the same and that is all they desire. This is quite true, and in the present state of our knowledge of medicines and their effects it is about all they can know; but would their ability to combat disease and administer medicines more scientifically and effectively not be many times increased if our knowledge of these same medicines and their effects and the cause of the effect, were known to them. They would then know that since, we will say for example, pilocarpine interferes with the functions of the liver it is not advisable to use this drug for a patient who requires a diaphoretic, but at the same time has a diseased liver. We might perhaps have learned by that time that a certain radical in the pilocarpine molecule pro. duced the untoward effect on the liver, but that pilocarpidine, while still an effective diaphoretic, no longer produced this effect on the liver, due to the elimination from its molecule of the undesirable radical present in the pilocarpine molecule. There can be no doubt of one thing, and that is that medicine in its narrow sense, $i$.e., the science of the administration of drugs, has not advanced at the same rate that the sciences of surgery, bacteriology, pathology or anatomy have during the last half century. In fact, many physicians have grown skeptical as to the value of drugs and think the less of them used, as a rule, the better. The development and future above outlined for the science of medicine in its narrower sense, will, unquestionably, remove all such skepticism and push therapeutics forward as a most necessary and invaluable requisite for the combating of disease. I may be pardoned when I say that scientific medicine, $i . e$, the scientific administration of drugs, is only in its infancy at present, and that most of our medicines are administered empirically, i.e., are administered not because we know exactly why they are what our particular case in hand calls for, but beeause experience has taught us that they are effective and will produce certain results. I do not wish to be misunderstood in this connection, and when I say the administration of medicines is largely empirical I do not mean to state or imply anything derogatory, but merely to say that our present knowledge of the administration of medicine does not enable us to do anything better. My purpose in going into this detail as to empiricism vs. science is merely to explain the meaning intended to be conveyed by the term scientific medicine in the title of the paper I am presenting. All physicians will agree that it is desirable to increase our knowl. edge of pharmacology and pharmaco-physics, for the more they know about the effects of drugs and their cause the better off they will be in successfully combating various diseases. There is one obstacle, however, to success in this direction in this country and which does not exist in Germany, and that is the indifference or unwillingness of hospital and clinics to take up and try, carefully and scientifically, any new preparations that may be offered them for expe- riment. The necessary thing to be done in this country to make the development and study of pharmacology successful, is the adoption of courses of lectures on these subjects, together with the opening of laboratories for their experimental study and research. In Germany chairs of pharmacology are established at almost every university, and at several of them the work in the lecture room is supplemented by actual experiments and actual investigations and study in the laboratory and clinic. Thus, the laboratories of Professor Schmiedeberg in Strasburg, Baumann in Freiburg, and Drechsel in Leipzig, are headquarters for this work in Germany, and their number is stead. ily growing. It has not been so many years ago that in order to study the new science of pathology one had to go to Berlin, to Virchow's laboratory, but Virchow has gradually developed other capable teachers and expounders of his theories and methods, and now pathology is a part of the course in medicine in practically every college in this country. So it will be with pharmacology and pharmaco-physics. The pupils of Schmiedeberg, Drechsel and Baumann will organize laboratories and courses, just as their instructors did, and the result will be that every school of medicine will embrace as part of its curriculum lectures and laboratory work on pharmacology, and perhaps also pharmaco-physics. Some schools of medicine have such courses already, as, for instance, Johns Hopkins, Harvard, Pennsylvania, Ann Arbor, etc., and others will unquestionably adopt the same in the near future. When this is brought about, the era for the scientific administration of drugs, $i$. $e$, scientific medicine, will set in, and the stepping-stones to reach that stage will be pharmaceutic chemistry, pharmacology and pharmaco-physics.

\section{THE NATURE OF THE LEUCOCYTOSIS PRODUCED BY NUCLEINIC ACID;} A PRELIMINARY EXPERIMENTAL STUDY.

Presented to the Section on Materia Medica, Pharmacy and Therapeutics, at te Forty-eighth Annual Meeting of the American Medical Association, Philadelphia, Pa., June 1-4, 1897.

BY DELANO AMES, A.B., M.D.

Lecturer on Pathology and Director of the Pathologic Laboratories in the Baltimore Medical College; Pathologist and Visiting Pbysician to the Maryland General Hospital; Pathologist to the Union Protestant Infirmary Hospital.

AND A. A. HUNTLEY, M.D.

Assistant Demonstrator of Patbologg in the Baltimore Medical College.

Within the past two or three years there has come into gradual prominence a system of therapeutics known popularly as nuclein therapy, which is attracting more and more attention and receiving a growing recognition at the hands of the medical profession.

The use of nuclein was first advocated on purely theoretic grounds, it being claimed that by its use the germicidal power of the blood could be increased and hence the resistance to diseases of germ origin heightened. Of late, however, certain writers have denied. that nuclein acts as it was supposed to, and in consequence, its use being founded on a false conception of its powers, have claimed that it was not beneficial.

The application of nuclein to the treatment of certain diseases, especially to certain of the infectious processes, seems to be attended with beneficial results, though the observations are as yet too few and too incomplete to be of much value. Such as they are, 